Pacific Journal of Mathematics

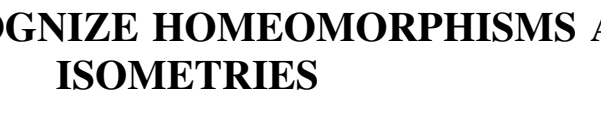




\title{
HOW TO RECOGNIZE HOMEOMORPHISMS AND ISOMETRIES
}

\author{
CARLOS R. BORGES
}

\begin{abstract}
We study necessary and sufficient conditions for a given function $f ; X \rightarrow X$ to be one-to-one, or a homeomorphism or a topological isometry ${ }^{1}$, by analyzing the family $\left\{f^{1}, f^{2}, \cdots\right\}$ of its composition iterates.
\end{abstract}

In $\S 1,2$ and 3 we develop the key results. (See Theorems 2.1 and 2.3).

In $\S 4$ we obtain a variety of applications, most of which are known, by various different techniques. They all follow easily from our key results:

(a) Conditions which imply that locally nonexpansive maps (in metric spaces or uniform spaces) become local isometries (see Theorem 4.2, Corollary 4.3 and Theorem 4.5, and also [2], [5] and [6]).

(b) Conditions which imply that a given map on a metrizable space is a topological isometry ${ }^{1}$ (see Theorems 4.6 and 4.7, and also $[8])$.

(c) Some results on compact commutative groups of homeomorphisms (or topological isometries) of $X$ onto $X$ (see Theorems 4.11 and 4.12, and also [4], [10] and [11]).

1. Auxiliary results. For each space $X$ we let $i d_{X}$ denote the identity function on $X$ and, for each continuous function $f: X \rightarrow X$, we let

(a) $f^{1}=f, f^{n}=f \circ f^{n-1}$ for $n>1$

(b) $P=\bigcap_{n=1}^{\infty} f^{n}(X)$

(c) $\Gamma(f)=\left\{f^{n} \mid n=1,2, \cdots\right\}^{-}$, the closure being with respect to the co. (i.e. compact-open) topology on the function space $X^{x}$.

Proposition 1.1. If $X$ is locally compact and Hausdorff then $X^{X}$ (and therefore also $\Gamma(f)$ ) is a topological semigroup with respect to composition.

Proof. Immediate from Theorem 2.2 (p. 259) of Dugundji [3].

Lemma 1.2. Suppose $X$ is compact Hausdorff and $\left\{f^{1}, f^{2}, \cdots\right\}$ is

1 We wish to thank Professors J. Dugundji, W. Comfort and A. D. Wallace for bringing to our attention references [6], [2] and [10] respectively. They strongly motivated us to sharp improvements of our original results. 
evenly continuous. Then $\Gamma(f)$ is compact.

Proof. By Theorem 19 (p. 235) of [7], $\Gamma(f)$ is evenly continuous since $\Gamma(f)$ is contained in the pointwise (topology) closure of $\left\{f^{1}, f^{2}, \cdots\right\}$. By Ascoli's Theorem (p. 236 of [7]), $\Gamma(f)$ is compact.

Lemma 1.3 Suppose $X$ is compact Hausdorff and $\left\{f^{1}, f^{2}, \cdots\right\}$ is evenly continuous. Then $\Gamma(f)$ has an idempotent $e$ (i.e. $e^{2}=e$ ) such that $e(X)=P$ and $e / P=i d_{P}$.

Proof. By our Lemma 1.2 and Theorem 3.1 of [9], $\Gamma(f)$ has an idempotent $e$ (the unit of the maximal nonempty subgroup $K(f)$ of $\Gamma(f))$.

We show $P \subset e(X)$ : Let $y \in P$. Then there exists $x_{n} \in X$ such that $f^{n}\left(x_{n}\right)=y$, for each $n$. Pick a subnet $\left\{\left(f^{\nu}, x_{2}\right)\right\}$ of $\left\{\left(f^{n}, x_{n}\right)\right\}$ such that $\lim _{\nu} f^{\nu}=e$. Then there exists $w \in X$ and a subnet $\left\{\left(f^{\lambda}, x_{\lambda}\right)\right\}$ of the net $\left\{\left(f^{\nu}, x_{\nu}\right)\right\}$ such that $\lim _{\lambda}\left(f^{\lambda}, x_{\lambda}\right)=(e, w)$, because $\Gamma(f) \times X$ is compact. Consequently $e(w)=\lim _{\lambda} f^{\lambda}\left(x_{\lambda}\right)=\lim _{\lambda} y=y$, because of Theorems 4.71 and 2.5 of [1].

We show $e(X) \subset P$ : Let $x \in X$ and pick subnet $\left\{f^{\nu}\right\}$ of $\left\{f^{n}\right\}$ such that $\lim f^{\nu}=e_{\text {. }}$ Then $e(x)=\lim _{\nu} f^{\nu}(x)$ and, since each $f^{n}(X)$ is a closed subset of $X$ (because $X$ is compact), $e(x) \in P$.

Clearly $e \mid P=i d_{P}$ since $e(e(x))=e(x)$ for each $x \in X$.

It appears that our main results become more meaningful when stated in terms of a generalization of the concept of "an almost periodic ${ }^{2}$ function" introduced by Whyburn [12], especially because of Lemma 1.5 below.

Definition 1.4. Let $f: X \rightarrow X$ be a function. Then $f$ is said to be net periodic if there exists a subnet $\left\{f^{\nu}\right\}$ of $\left\{f^{n}\right\}$ with $\lim _{\nu} f^{\nu}=i d_{X}$ (in $X^{x}$ ).

Clearly net periodicity is equivalent to almost periodicity whenever $X^{X}$ is metrizable.

Lemma 1.5. Let $f: X \rightarrow X$ be net periodic. Then $f$ is one-to-one.

Proof. Suppose $f(x)=f(y)$. Then $f^{n}(x)=f^{n}(y)$. for all n.Pick subnet $\left\{f^{\nu}\right\}$ of $\left\{f^{n}\right\}$ such that $\lim _{\nu} f^{\nu}=i d_{X}$. Then $i d_{X}(x)=\lim _{\nu} f^{\nu}(x)=$ $\lim _{\nu} f^{\nu}(y)=i d_{X}(y)$ implies that $x=y$. This does the trick.

${ }^{2}$ For any metric space $(X, \rho)$ a function $f: X \rightarrow X$ is said to be almost periodic (see [12]) if for each $\varepsilon>0$ there exists a positive integer $n$ such that $\rho\left(f^{n}(x), x\right)<\varepsilon$ for all $x \in X$. This is clearly equivalent to saying that there exists a subsequence $\left\{f^{n_{i}}\right\}$ of $\left\{f^{n}\right\}$ which converges uniformly to the identity function of $X$. 
Lemma 1.6. Let $X$ be compact Hausdorff and $f: X \rightarrow X$ a continuous function. If $f$ is net periodic then $f$ is an onto homeomorphism.

Proof. Because of Lemma 1.5 we only need prove that $f$ is onto: Suppose not. Then $X-f(X)$ is an open nonempty subset of $X$. Let $\left\{f^{\nu}\right\}$ be a subnet of $\left\{f^{n}\right\}$ such that $\lim f^{\nu}=i d_{X}$. Then for any $a \in X-f(X), \quad \lim _{\nu} f^{\nu}(a)=a$ while $f^{\nu}(X) \subset f(X)$ (i.e. $f^{\nu}(X) \cap$ $[X--f(X)]=\varnothing)$ for all $\nu$. This is a contradiction.

\section{Main results.}

THEOREM 2.1 Let $X$ be compact Hausdorff and $f: X \rightarrow X$ a function. If $\left\{f^{1}, f^{2}, \cdots\right\}$ is evenly continuous then $f \mid P$ is net periodic (and therefore a homeomorphism).

Proof. By Lemma 1.3, there exists an idempotent $e \in \Gamma(f)$ such that $e \mid P=i d_{P}$. Consequently there exists a subnet $\left\{f^{\nu}\right\}$ of $\left\{f^{n}\right\}$ with $\lim _{\nu} f^{\nu}=e$ (even if $e=f^{n}$ for some $n$ ) which implies that $\lim _{\nu} f^{\nu} \mid P=$ $e \mid P=i d_{P}$. Since $f(P)=P$ (because $f^{n}(X) \supset f^{n+1}(X) \supset P$ for all $n$ ) we get that $f^{\nu} \mid P=(f \mid P)^{\nu}$. Therefore $\lim _{\nu}(f \mid P)^{\nu}=i d_{P}$ and $f \mid P$ is net periodic.

Corollary 2.2. Let $X$ be compact Hausdorff and $f: X \rightarrow X$ an onto function. If $\left\{f^{1}, f^{2}, \cdots\right\}$ is evenly continuous then $f$ is net periodic (and therefore a homeomorphism).

Since the converse of Theorem 2.1 is false (for example, let $f: I \rightarrow I$ be defined by $f(t)=t^{2}$, where $I$ denotes the closed unit interval), the following seems worthy of mention.

THEOREM 2.3. Let $X$ be any space and $f: X \rightarrow Y$ a continuous function. Then $f$ is one-to-one if and only if $\Gamma(f)$ contains a oneto-one function.

Proof. The "only if" part is clear. To prove the "if" part let $e: X \rightarrow X$ be any one-to-one function such that $e \in L(f)$. Assume $f(x)=f(y)$. Then $f^{n}(x)=f^{n}(y)$ for all $n$ and one easily sees that $e(x)=e(y)$. (This is clear if $e=f^{n}$ for some $n$. Otherwise there exists a subnet $\left\{f^{\nu}\right\}$ of $\left\{f^{n}\right\}$ with $\lim _{\nu} f^{\nu}=e$. Therefore $e(x)=$ $\left.\lim _{\nu} f^{\nu}(x)=\lim _{\nu} f^{\nu}(y)=e(y)\right)$. This shows that $f$ is one-to-one.)

3. Generalizations. With some additional restrictions on $f$, 
Theorem 2.1 remains valid for a larger class of spaces.

Throughout this section we let $E$ be a noncompact, locally compact, space, and $\hat{E}=E \cup\{\infty\}$ be its one-point compactification. Also for each onto map $f: E \rightarrow E$ we consider the three conditions:

(A) For each sequence $\left\{x_{n}\right\}$ in $E, \lim _{n} x_{n}=x \neq \infty$ and $\lim _{n} f^{i_{n}}(x)=$ $\infty$ implies that $\lim _{n} f^{i_{n}}\left(x_{u}\right)=\infty$,

(B) For each sequence $\left\{x_{n}\right\}$ in $E, \lim _{n} x_{n}=\infty$ implies that $\lim _{n} f^{i_{n}}\left(x_{n}\right)=\infty$,

(C) For each sequence $\left\{x_{n}\right\}$ in $E, \lim _{n} x_{n}=\infty$ implies that $\lim _{n} f\left(x_{n}\right)=\infty$.

In Example 5.1, it is shown that conditions (A) and (C) do not imply (B).

LEMMA 3.1. Condition (C) is satisfied if $f$ is either (a) uniformly continuous with respect to some compatible metric on $\hat{E}$ (assuming $E$ is separable metrizable), or (b) a homeomorphism.

Proof. (a) Since $\hat{E}$ is completely metrizable we can continuously extend $f$ to $\hat{f}: \hat{E} \rightarrow \hat{E}$. Since $E$ is not compact, $\hat{f}(\infty)=\infty$. This shows that $f$ satisfies $(C)$.

(b) Suppose $\lim _{\nu} x_{\nu}=\infty$ but $\lim _{\nu} f\left(x_{\nu}\right) \neq \infty$. Then there exists a subsequence $\left\{x_{\sigma}\right\}$ of $\left\{x_{\nu}\right\}$ such that $\lim _{\sigma} x_{\sigma}=\infty \lim _{\sigma} f\left(x_{\sigma}\right)=y$ for some $y \in E$. Then $f^{-1}(y)=\lim _{\sigma} f^{-1} f\left(x_{\sigma}\right)=\lim _{\sigma} x_{\sigma}=\infty$, which is impossible.

Lemma 3.2. Condition $(B)$ implies $(C)$. (The converse is falsesee Example 5.1.)

Proof. Simply let all $i_{n}=1$ in $(B)$.

Lemma 3.3. If $E$ is metrizable and $f: E \rightarrow E$ is nonexpansive (with respect to some compatible metric $d$ on $E$ ) then $f$ satisfies conditions $(\mathrm{A})$ and $(\mathrm{C})$.

Proof. (That $f$ satisfies (A) is essentially proved in the proof of Theorem 1.1 of [8]. We present a simpler argument.) Suppose that $\lim _{n} x_{n}=x \in E, \lim _{n} f^{i_{n}(x)=\infty}$ but $\lim _{n} f^{i_{n}}\left(x_{n}\right) \neq \infty$. Then there exists compact $C \subset E, z \in C$ and subsequence $\{\beta\}$ of the integers such that $f^{i_{\beta}}\left(x_{\beta}\right) \in C$ and $\lim _{\beta} f^{i_{\beta}}\left(x_{\beta}\right)=z$. Since $d\left(f^{i_{\beta}}\left(x_{\beta}\right), f^{i_{\beta}}(x)\right) \leqq d\left(x_{\beta}, x\right)$, we get that $\lim _{\beta} f^{i_{\beta}}\left(x_{\beta}\right)=z$, a contradiction. Similarly, one can easily see that $f$ satisfies $(C)$.

THEOREM 3.4. Let $f: E \rightarrow E$ be an onto function such that 
$\left\{f^{1}, f^{2}, \cdots\right\}$ is evenly continuous and $f$ satisfies conditions (A) and (B). Then $f$ extends continuously to an onto function $\hat{f}: \hat{E} \rightarrow \widehat{E}$ such that $\left\{f^{1}, f^{2}, \cdots\right\}$ is evenly continuous. (Therefore, $f$ and $\hat{f}$ are net periodic.)

Proof. Since $f$ satisfies $(C)$, by Lemma 3.2, we can extend $f$ to $\hat{f}: \hat{E} \rightarrow \hat{E}$ continuously, by letting $\hat{f}(\infty)=\infty$. Because of (A) and (B) it is easily seen that $\left\{\hat{f}^{1}, \hat{f}^{2}, \cdots\right\}$ is evenly continuous. Therefore, by Theorem 2.1, $\hat{f}$ is net periodic. This completes the proof.

Example 5.1 shows that if $f$ does not satisfy $(B)$ then $f$ is not necessarily net periodic.

\section{Applications.}

Definition 4.1. Let $(X, \rho)$ be a metric space. A function $f: X \rightarrow X$ is said to be locally nonexpansive if each $p \in X$ has a neighborhood $N_{p}$ such that $\rho(f(x), f(y)) \leqq \rho(x, y)$ for all $x, y \in N_{p}$. If $N_{n}=$ $X$ then $f$ is said to be nonexpansive. If, for come $\varepsilon>0, \rho(x, y)<\varepsilon$ implies that $\rho(f(x), f(y)) \leqq \rho(x, y)$, then $f$ is said to be $\varepsilon$-nonexpansive. Replacing "ฏ" by "=" above, we get the definitions of local isometry and of $\varepsilon$-isometry.

Theorem 4.2. Let $(X, \rho)$ be a compact metric space and $f: X \rightarrow X$ a locally nonexpansive onto function. Then $f$ is almost periodic ${ }^{2}$ and therefore a local isometry.

Proof. By compactness of $X$, there exists $\varepsilon>0$ such that $f$ is $\varepsilon$-nonexpansive. By the net characterization of even continuity (cf. exercise $L$ on p. 241 of [7]) it is easy to prove that $\left\{f^{1}, f^{2}, \cdots\right\}$ is evenly continuous (for each net (in this case, sequences suffice)

$$
\left\{\left(f^{\nu}, x_{\nu}\right)\right\} \subset\left\{f^{1}, f^{2}, \cdots\right\} \times X, \lim _{\nu} x_{\nu}=x \text { and } \lim _{\nu} f^{\nu}(x)=y
$$

implies that

$$
\rho\left(f^{\nu}\left(x_{\nu}\right), y\right) \leqq \rho\left(f^{\nu}\left(x_{\nu}\right), f^{\nu}(x)\right)+\rho\left(f^{\nu}(x), y\right) \leqq \rho\left(x_{\nu}, x\right)+\rho\left(f^{\nu}(x), y\right)
$$

for all $\nu$ with $\rho\left(x_{\nu}, x\right)<\varepsilon$, since each $f^{n}$ is also $\varepsilon$-nonexpansive; therefore $\lim _{\nu} f^{\nu}\left(x_{\nu}\right)=y$, which does the trick).

Since $f$ is onto, we get that $P=X$ and therefore that $f$ is almost periodic, by Theorem 2.1 (and footnote 2).

It is now easily seen that $f$ is a local isometry (pick subnet $\left\{f^{\nu}\right\}$ of $\left\{f^{n}\right\}$ with $\lim _{\nu} f^{\nu}=i d_{x}$. Since 


$$
\rho(x, y) \leqq \rho\left(x, f^{\nu}(x)\right)+\rho\left(f^{\nu}(x), f^{\nu}(y)\right)+\rho\left(f^{\nu}(y), y\right)
$$

we get that $\rho(x, y) \leqq \lim _{\nu} \rho\left(f^{\nu}(x), f^{\nu}(y)\right)$ for all $x, y \in X$. If

$$
\rho\left(f(a), f^{\nu}(b)\right)<\rho(a, b)<\varepsilon,
$$

for some $a, b \in X$, then

$$
\rho\left(f^{\nu}(a), f^{\nu}(b)\right) \leqq \rho(f(a), f(b))<\rho(a, b), \quad \text { for all } \nu,
$$

which implies that $\lim _{\nu} \rho\left(f^{\nu}(a), f^{\nu}(b)\right)<\rho(a, b)$, a contradiction). This completes the proof.

Corollary 4.3 (Satze Ib of [6] and Theorem 1 of [5]). Let $(X, \rho)$ be a totally bounded metric space and $f: X \rightarrow X$ an $\varepsilon$-nonexpansive map such that $f(X)$ is dense in $X$. Then $f$ is an e-isometry and $X$ is dense in $f(X)$.

Proof. Let $\hat{X}$ be the usual metric completion (in terms of Cauchy sequences-see Theorem 27 on p. 196 of [7]). Since $f(X)$ is dense in $X$ then $\hat{X}$ is also the completion of $f(X)$. Clearly $\hat{X}$ is compact metrizable by a metric $\hat{\rho}$ which extends $\rho$, and $f$ is extendable to a continuous function (because $f$ is uniformly continuous) $\hat{f}: \hat{X} \rightarrow \hat{X}$ such that $\hat{f}$ is an onto map (because of compactness). It is also easily seen that $\hat{f}$ is $\varepsilon$-nonexpansive (Let $x, y \in \hat{X}$ with $\hat{\rho}(x, y)<\varepsilon$. Pick nets (sequences suffice) $\left\{x_{\nu}\right\},\left\{y_{\nu}\right\}$ in $X$ with $\lim _{\nu} x_{\nu}=x, \lim _{\nu} y_{\nu}=y$ and $p\left(x_{\nu}, y_{\nu}\right)<\varepsilon$ for all $\nu$ (this can be done because of the definition of $\hat{\rho})$. Then $\hat{\rho}(\hat{f}(x), \hat{f}(y))=\lim _{\nu} \rho\left(f\left(x_{\nu}\right), f\left(y_{\nu}\right)\right) \leqq \lim _{\nu} \rho\left(x_{\nu}, y_{\nu}\right)=\hat{\rho}(x, y)$, because $\rho(x, y)<\varepsilon)$. Theorem 4.2 completes the proof.

DeFinition 4.4. Let $(X, \mathscr{Z})$ be a uniform space and $\theta=\left\{\rho_{X}\right\}_{\text {R. }}$ a gage (see p. 188 of [7]) for $\mathscr{U}$. A function $f: X \rightarrow X$ is said to be $\varepsilon$-nonexpansive with respect to $\theta(\varepsilon<0)$ if $\rho_{\lambda}(x, y)<\varepsilon$ implies that $\rho_{\lambda}(f(x), f(y)) \leqq \rho_{\lambda}(x, y)$, for each $\lambda \in \Lambda$. If $f$ is $\varepsilon$-nonexpansive with respect to $\theta$ for all $\varepsilon>0$ then $f$ is said to be nonexpansive with respect to $\theta$. Replacing " $<$ " by "=" above we get the definitions of $\varepsilon$-isometry and of isometry with respect to $\theta$.

THEOREM 4.5. Let $(X, \mathscr{C})$ be a uniform compact Hausdorff space and $f: X \rightarrow X$ an onto $\varepsilon$-nonexpansive map with respect to some gage $\theta=\left\{\rho_{\lambda\}_{n \in A}}\right.$ for $\%$. Then $f$ is net periodic and an E-isometry with respect to $\theta$.

Proof. All the statements in the proof of Theorem 4.2 which involve $\rho$ remain valid when $\rho$ is replaced by any $\rho_{\lambda} \in \theta$. Therefore, 
by use of Theorem 19 on p. 189 of [7], one immediately gets that $\left\{f^{1}, f^{2}, \cdots\right\}$ is evenly continuous, and $f$ is net periodic and and an $\varepsilon$ isometry with respect to $\theta$. This completes the proof.

Brown and Comfort [2] have obtained a similar result for totally bounded Hausdorff uniform spaces.

With respect to topological isometries we get the following results, of which the first shows that the hypothesis that $f$ be a homeomorphism in Corollary 1.2 of [8] is superfluous; the second complements Theorem 1.1 of [8].

THEOREM 4.6. Let $f: M \rightarrow M$ be a function from the compact metrizable space $M$ onto itself. Then $f$ is a topological isometry if and only if $\left\{f^{1}, f^{2}, \cdots\right\}$ is evenly continuous.

Proof. Immediate from Corollary 1.2 of [8] and our Theorem 2.1.

THEOREM 4.7. Let $f: E \rightarrow E$ be a function from the separable locally compact metrizable space $E$ onto itself. Then $f$ is the restriction of a topological isometry $\hat{f}: \hat{E} \rightarrow \hat{E}$ if and only if $\left\{f^{1}, f^{2}, \cdots\right\}$ is evenly continuous and $f$ satisfies conditions (A) and (B).

Proof. Immediate from Theorems 4.6 and 3.4 .

Finally we get some results on transformation groups. But first we need the following three lemmas.

LEMma 4.8. Let $f: X \rightarrow X$ be a function from a compact Hausdorff space $X$ onto itself. If $\left\{f^{1}, f^{2}, \cdots\right\}$ is evenly continuous then $\left\{f^{-1}, f^{-2}, \cdots\right\} \subset \Gamma(f)$ and it is evenly continuous.

Proof. By Corollary 2.2, $f^{-1}$ is a well-defined function and there exists subnet $\left\{f^{\nu}\right\}$ of $\left\{f^{m}\right\}$ with $\lim _{\nu} f^{\nu}=1_{X}$. Therefore

$$
\lim _{\nu} f^{-1} f^{\nu}=\lim _{\nu} f^{\nu-1}=f^{-1} 1_{X}=f^{-1} \in \Gamma(f) \text {. }
$$

Similarly one proves that $\left\{f^{-1}, f^{-2} \cdots\right\} \subset \Gamma(f)$. Therefore $\left\{f^{-1}, f^{-2} \cdots\right\}$ is evenly continuous, since $\Gamma(f)$ is compact by Lemma 1.2. This completes the proof.

Lemma 4.9. Let $f: X \rightarrow X$ be a function from a compact Hausdorff space $X$ onto itself. If $\left\{f^{1}, f^{2}, \cdots\right\}$ is evenly continuous then, $\lim _{\nu} f^{\nu}(x)=y$ if and only if $\lim _{\nu} f^{-\nu}(y)=x$, for any given net $\left\{f^{\nu}\right\}$.

Proof. (Essentially contained in the proof of Corollary 1.3 of [8].) 
Let $\lim _{\nu} f^{\nu}(x)=y$ and assume $\lim _{\nu} f^{-\nu}(y) \neq x$. Then there exists a neighborhood $\mathscr{C}$ of $x$, some $z \in X-\mathscr{U}$, and a subnet $\left\{f^{-\alpha}(y)\right\}$ of $\left\{f^{-\nu}(y)\right\}$ with $\lim _{\alpha} f^{-\alpha}(y)=z$. Since $\lim _{\alpha} f^{\alpha}(x)=y$, by the net characterization of even continuity (of $\left\{f^{-1}, f^{-2}, \cdots\right\}$, by Lemma 4.8) we then get that

$$
z=\lim _{\alpha} f^{-\alpha} f^{\alpha}(x)=\lim _{\alpha} x=x,
$$

a contradiction. This does the trick.

Lemma 4.10. Let $f: X \rightarrow X$ be a function from the compact Hausdorff space $X$ onto itself. If $\left\{f^{1}, f^{2}, \cdots\right\}$ is evenly continuous, then any $g \in \Gamma(f)$ is an onto homeomorpism of $X$.

Proof. Pick net $\left\{f^{\nu}\right\}$ in the (evenly continuous family) $\left\{f^{1}, f^{2}, \cdots\right\}$ with $\lim _{\nu} f^{\nu}=g$ and assume $g(p)=\lim _{\nu} f^{\nu}(p)=\lim _{\nu} f^{\nu}(q)=g(q)$. Then, by Lemma 4.9, $p=\lim _{\nu} f^{-\nu}(g(p))=\lim _{\nu} f^{-\nu}(g(q))=q$, and this shows that $g$ is one-to-one.

For any $p \in X$ and each $\nu$, there exists $p_{\nu} \in X$ with $f^{\nu}\left(p_{\nu}\right)=p$. Pick subnet $\left\{f^{\sigma}\right\}$ of $\left\{f^{\nu}\right\}$ and $w, z \in X$ with $\lim _{\sigma} p_{\sigma}=z$ and $\lim _{\sigma} f^{\sigma}(z)=w$. Then, by even continuity, $w=\lim _{\sigma} f^{\sigma}\left(p_{\sigma}\right)=\lim _{\sigma} p=p$.

THEOREM 4.11. Let $f: X \rightarrow X$ be a function from the compact Hausdorff space $X$ onto itself. If $\left\{f^{1}, f^{2}, \cdots\right\}$ is evenly continuous then $\Gamma(f)$ is a compact commutative group of homeomorphisms of $X$ onto $X$.

Proof. Immediate from Lemma 4.10. $(\Gamma(f)$ is commutative because it is the closure of a commutative group.)

This result is similar to Theorem 2 of Wallace [10] and a result of Wallace [11].

THEOREM 4.12. Let $f: M \rightarrow M$ be a function from the compact metrizable space $M$ onto itself. If $\left\{f^{1}, f^{2}, \cdots\right\}$ is evenly continuous then there exists a compatible metric $d$ for $M$ such that $\Gamma(f)$ is a commutative group of $d$-isometries acting on $M$.

Proof. By Theorem 4.6, $f$ it a $d$-isometry for some compatible metric $d$ for $M$. It is easily seen that also each $g \in \Gamma(f)$ is a $d$ isometry.

5. Counterexamples. The following example illustrates that most of the hypothesis in our main results are not superfluous. 
EXAMPLE 5.1. There exists a nonexpansive onto function $f$ : $E^{1} \rightarrow E^{1}$ ( $E^{1}$ is the real line) such that

(a) $f$ is not net periodic and dose not satisfy (B),

(b) of course, $f$ satisfies conditions (A) and (C), and $\left\{f^{1}, f^{2}, \cdots\right\}$ is evenly continuous.

Proof. Let $f: E^{1} \rightarrow E^{1}$ be defined by

$$
\begin{array}{lrl}
f(x) & =x & \text { for each } x<0 \\
f(x) & =0 & \text { for all } 0 \leqq x \leqq 1 \\
f(x) & =x-1 & \text { for all } x>1 .
\end{array}
$$

Clearly $f$ is onto and nonexpansive. (Note that $f^{n}(x)=x$ for $x<0$, $f^{n}(x)=0$ for $0 \leqq x \leqq n$ and $f^{n}(x)=x-n x>n$. Therefore $\lim _{n} n=\infty$ but $\lim _{n} f^{n}(n)=0$ ).

\section{REFERENCES}

1. R. Arens and J. Dugundji, Topologies for function spaces. Pacific J. Math., 1 (1951), 53-1.

2. T. Brown and W. Comfort, New method for expansion and contraction maps in uniform spaces, Proc. Amer. Math. Soc., 11 (1960), 483-486.

3. J. Dugundji, Topology, Allyn and Bacon, Boston 1966.

4. A. Edrei, On iteration of mappings of a metric space onto itself, J. London Math. Soc., 26 (1951), 96-103.

5. - On mappings which do not increase small distances, Proc. London Math. Soc., 2 (1952), 272-278.

6. H. Freudenthal and W. Hurewicz, Dehnungen, Verkurzungen, Isometrien, Fund. Math., 26 (1936), 120-122.

7. J. L. Kelley, General Topology, Van Nostrand, 1955.

8. M. M. Marjanovic, On topological isometrics, Indag. Math. 31 (1960), 184-189.

9. A. D. Wallace, The structure of topological semigroups, Bull. Amer. Math. Soc., 61 (1955), 95-112.

10. - The gebietstreue in semigroups, Indag. Math., 18 (1956), 271-274.

11. L Inverses in Euclidean mobs, Math. J. Okayama, Univ., 3 (1953), 1-3.

12. G. T. Whyburn, Analytic Topology, Amer. Math. Soc. Colloq. Publications, Vol. 28.

Received May 4, 1970.

University of CALIFornia, Davis 



\title{
PACIFIC JOURNAL OF MATHEMATICS
}

\author{
EDITORS
}

\author{
H. SAMelson \\ Stanford University \\ Stanford, California 94305 \\ C. R. HoBBy \\ University of Washington \\ Seattle, Washington 98105
}

J. DugunduI

Department of Mathematics

University of Southern California

Los Angeles, California 90007

RICHARD ARENS

University of California

Los Angeles, California 90024

\section{ASSOCIATE EDITORS}

\author{
E. F. BeCKENBACH
}

B. H. NEUMANN

F. WoLF

K. YOSHIDA

\section{SUPPORTING INSTITUTIONS}

\author{
UNIVERSITY OF BRITISH COLUMBIA \\ CALIFORNIA INSTITUTE OF TECHNOLOGY \\ UNIVERSITY OF CALIFORNIA \\ MONTANA STATE UNIVERSITY \\ UNIVERSITY OF NEVADA \\ NEW MEXICO STATE UNIVERSITY \\ OREGON STATE UNIVERSITY \\ UNIVERSITY OF OREGON \\ OSAKA UNIVERSITY \\ UNIVERSITY OF SOUTHERN CALIFORNIA
}

\author{
STANFORD UNIVERSITY \\ UNIVERSITY OF TOKYO \\ UNIVERSITY OF UTAH \\ WASHINGTON STATE UNIVERSITY \\ UNIVERSITY OF WASHINGTON \\ AMERICAN MATHEMATICAL SOCIETY \\ CHEVRON RESEARCH CORPORATION \\ NAVAL WEAPONS CENTER
}

The Supporting Institutions listed above contribute to the cost of publication of this Journal, but they are not owners or publishers and have no responsibility for its content or policies.

Mathematical papers intended for publication in the Pacific Journal of Mathematics should be in typed form or offset-reproduced, (not dittoed), double spaced with large margins. Underline Greek letters in red, German in green, and script in blue. The first paragraph or two must be capable of being used separately as a synopsis of the entire paper. The editorial "we" must not be used in the synopsis, and items of the bibliography should not be cited there unless absolutely necessary, in which case they must be identified by author and Journal, rather than by item number. Manuscripts, in duplicate if possible, may be sent to any one of the four editors. Please classify according to the scheme of Math. Rev. Index to Vol. 39. All other communications to the editors should be addressed to the managing editor, Richard Arens, University of California, Los Angeles, California, 90024.

50 reprints are provided free for each article; additional copies may be obtained at cost in multiples of 50 .

The Pacific Journal of Mathematics is published monthly. Effective with Volume 16 the price per volume (3 numbers) is $\$ 8.00$; single issues, $\$ 3.00$. Special price for current issues to individual faculty members of supporting institutions and to individual members of the American Mathematical Society: $\$ 4.00$ per volume; single issues $\$ 1.50$. Back numbers are available.

Subscriptions, orders for back numbers, and changes of address should be sent to Pacific Journal of Mathematics, 103 Highland Boulevard, Berkeley, California, 94708.

PUBLISHED BY PACIFIC JOURNAL OF MATHEMATICS, A NON-PROFIT CORPORATION

Printed at Kokusai Bunken Insatsusha (International Academic Printing Co., Ltd.), 7-17, Fujimi 2-chome, Chiyoda-ku, Tokyo, Japan. 


\section{Pacific Journal of Mathematics}

\section{Vol. 37, No. $3 \quad$ March, 1971}

Mohammad Shafqat Ali and Marvin David Marcus, On the degree of the

minimal polynomial of a commutator operator ................ 561

Howard Anton and William J. Pervin, Integration on topological

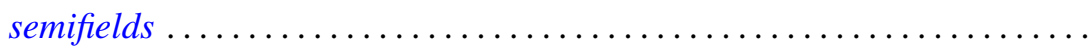

Martin Bartelt, Multipliers and operator algebras on bounded analytic

functions .................................... 575

Donald Earl Bennett, Aposyndetic properties of unicoherent continua ...... 585

James W. Bond, Lie algebras of genus one and genus two ............. 591

Mario Borelli, The cohomology of divisorial varieties ............... 617

Carlos R. Borges, How to recognize homeomorphisms and isometries ....... 625

J. C. Breckenridge, Burkill-Cesari integrals of quasi additive interval

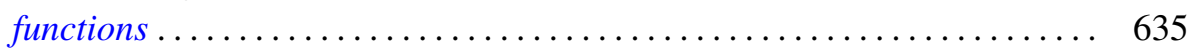

J. Csima, A class of counterexamples on permanents ................ 655

Carl Hanson Fitzgerald, Conformal mappings onto $\omega$-swirly domains . . . . . . 657

Newcomb Greenleaf, Analytic sheaves on Klein surfaces .............. 671

G. Goss and Giovanni Viglino, C-compact and functionally compact

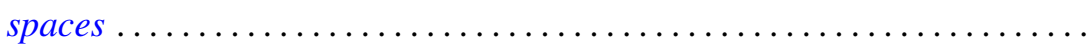

Charles Lemuel Hagopian, Arcwise connectivity of semi-aposyndetic plane

continua ..................................... 683

John Harris and Olga Higgins, Prime generators with parabolic limits ...

David Michael Henry, Stratifiable spaces, semi-stratifiable spaces, and their

relation through mappings .......................

Raymond D. Holmes, On contractive semigroups of mappings ........... 701

Joseph Edmund Kist and P. H. Maserick, BV-functions on semilattices ....... 711

Shûichirô Maeda, On point-free parallelism and Wilcox lattices ........... 725

Gary L. Musser, Linear semiprime $(p ; q)$ radicals ................. 749

William Charles Nemitz and Thomas Paul Whaley, Varieties of implicative

semilattices..................................... 759

Jaroslav Nešetřil, A congruence theorem for asymmetric trees ............ 771

Robert Anthony Nowlan, A study of $H$-spaces via left translations .......... 779

Gert Kjærgaard Pedersen, Atomic and diffuse functionals on a $C^{*}$-algebra ... 795

Tilak Raj Prabhakar, On the other set of the biorthogonal polynomials

suggested by the Laguerre polynomials...

801

Leland Edward Rogers, Mutually aposyndetic products of chainable



Frederick Stern, An estimate for Wiener integrals connected with squared

error in a Fourier series approximation.

Leonard Paul Sternbach, On k-shrinking and k-boundedly complete basic

sequences and quasi-reflexive spaces .................... 817

Pak-Ken Wong, Modular annihilator $A^{*}$-algebras ........ 